\title{
Food-dependent individual growth and population dynamics in fishes*
}

\author{
L. Perssontt and A. M. De Roos \\ $\dagger$ Department of Ecology and Environmental Science, Umea University, S-901 87 Umeå, \\ Sweden and §Institute of Biodiversity and Ecosystems, University of Amsterdam, \\ P. O. Box 94084, NL-1090 GB Amsterdam, The Netherlands
}

\begin{abstract}
It is long since well established that growth and development in fish individuals are heavily dependent on food intake. Yet, this dependence of individual development on food levels has only to a limited extent been taken into consideration when studying fish population and community processes. Using the modelling framework of physiologically structured population models and empirical data for a number of species configurations, how different size-dependent processes may affect fish population dynamics and community structures are reviewed. Considering competitive interactions, cohort interactions will often give rise to cohort cycles driven by an inequality in competitive abilities between differently sized individuals. The addition of cannibalism may dampen these cycles, the extent to which is dependent on lifehistory characteristics of the cannibals. The circumstance that individuals change their trophic position over their life cycle as a result of an increase in size gives rise to life history omnivory. In such omnivorous systems, food-dependent growth demotes the potential for predatory and prey fishes to coexist. In tritrophic food chains, food-dependent growth in the intermediate consumer may lead to the presence of bistability including sensitivity to catastrophic behaviour. These results shed new light on the drastic decreases observed in the stocks of many marine fish top predators including their inability to recover after fishing moratoria, and on the suggested presence of alternative states in freshwater fish communities.

(C) 2006 The Authors
\end{abstract}

Journal compilation $\odot 2006$ The Fisheries Society of the British Isles

Key words: cannibalism; cohort cycles; community structure; food-dependent growth; sizedependent interactions.

\section{INTRODUCTION}

For an ecologist in general the term growth applied to populations intuitively means the change (negative or positive) in number of individuals through birth, death and dispersal. For a fish ecologist, the perception of growth is more multifaceted as growth in fish populations can be discussed at two levels: the growth of individuals in the populations and the growth of populations consisting of these individuals. This fact was clearly noted already by Backiel \& Le Cren (1978): 'The very definition of biological production of fish populations implies consideration of two basic parameters: growth of individuals and their

*The fifteenth J.W. Jones Lecture.

\#Author to whom correspondence should be addressed. Tel.: +46 90-7866316; fax: +46 90-7866705; email: lennart.persson@emg.umu.se 
number'. Moreover, a connection between the two aspects of growth was considered by Beverton \& Holt (1957) in their classical paper on the dynamics of exploited fish populations as the "variation of (individual) growth with density in fish populations, is perhaps the best established of the density-dependent effects which we consider in this paper...'. To understand the production and dynamics of fish populations and their response to harvesting is hence a multidimensional problem as it is necessary to consider not only changes in numbers but also changes in size distributions.

The variation in individual growth with density in fish populations comes about because growth is strongly dependent upon food availability. Numerous studies on the energetics of fishes have quantified relationships between available food ration (related to density) and individual growth (Webb, 1978; Brett, 1995; Jobling, 2002). The effects of food on growth of individual fish have also been known by fish culturists for centuries. Ivlev (1961) developed models to describe the relationship between the amount of food consumed and food concentration, and since then numerous empirically parameterized models have been developed to describe individual consumption (linked to growth) as a function of food ration (Webb, 1978; Elliott, 1994; Jobling, 2002). The results of these studies have also been extended to the field to estimate food consumption of fish including their impact on the food resource using bioenergetics modelling (Kitchell et al., 1977).

Although the relationship between population and individual growth, and the food dependency of individual growth have been recognized in the literature, relatively few attempts have been made to link these different elements of the dynamics of fish populations into a formal framework. Rather, most fish population models are typically age or stage based assuming a fixed age-size relationship (Schnute \& Richards, 2001; Shepherd \& Pope, 2002). The purpose of this paper was to give an overview of the implications of size-dependent interactions and food-dependent growth on the dynamics of fish populations. A modelling framework, physiologically structured population (PSP) models, that is based on an explicit link between individual-level processes such as individual growth and population processes (Metz \& Diekmann, 1986; Metz et al., 1988; De Roos et al., 1990; De Roos, 1997) is first reviewed. This is followed by a description of themodelling process including the formulation of food-dependent gathering capacities and a discussion of the effects of cohort competition and cannibalism on population dynamics. The consequences of size-dependent predation and fooddependent growth in multispecies systems are then considered with the focus on how food-dependent growth may give rise to alternative community states. The framework of PSP models can be used as a tool in short-term (within-generation) studies to elucidate mechanisms driving observed dynamics. Finally, how the complexity of physiologically structured models can be reduced to allow the study of many species food webs is discussed.

\section{PHILOSOPHY OF PHYSIOLOGICALLY STRUCTURED POPULATION MODELS}

PSP models are in contrast to traditional population models based on a state definition at each of two levels of organization: an $i$-state model which represents the state of the individual in terms of a collection of characteristic 
physiological traits (e.g. size, age, sex and energy reserves), and a $p$-state model which is the frequency distribution over the space of possible $i$-states (Metz \& Diekmann, 1986; Metz et al., 1988; De Roos et al., 1990; De Roos, 1997). This population framework is specifically designed to handle the dynamics of sizestructured populations. The model formulation process consists of the derivation of a mathematical description of how individual performance (growth, survival and reproduction) depends on the physiological characteristics of the individual and the condition of the environment ( $i$-state description). Handling the population-level ( $p$-state) dynamics is subsequently just a matter of bookkeeping of all individuals in different states, and no further model assumptions are made at this level. The core of PSP models is thus the individual state and the changes therein. While bookkeeping provides the link from the individual to the population level, the reverse link is through the population feedback on individual life history and behaviour. For example, in a consumer-resource system the population influence on consumer life history operates through an increased or decreased density of resource, which affects individual growth, mortality and reproduction.

PSP models as defined above are also referred to as $i$-state distribution models (Caswell \& John, 1992), and are individual based in the sense that all modelling and hence all assumptions pertain to the individual life history. The model of the individual life history is still deterministic and assumes that individuals born at the same time and with the same $i$-state will remain identical throughout their entire life. This assumption implies that PSP models incorporate less flexibility to describe the fate of single individuals compared to individual-by-individual simulation models that account for each individual organism as a distinct entity and describe its dynamics by means of a set of rules. The latter models have been referred to as $i$-state configuration models, and are relevant to use for small population sizes when stochastic events may be influential for the dynamics, and when interactions are local (individual-byindividual) (Caswell \& John, 1992). One limitation of $i$-state configuration models is that they require a large number of replicates for the same parameter set to assess the ultimate dynamics, where the (deterministic) PSP models only require a single numerical integration. Moreover, for PSP models reliable numerical integration methods exist (De Roos et al., 1992; De Roos, 1997), as well as mathematical techniques to compute equilibria and carrying out bifurcation analysis (Kirkilionis et al., 2001; Claessen \& De Roos, 2003; Diekmann et al., 2003). Consequently, it can be argued that PSP models are better suited to investigate broader ecological questions about the interplay of individual life history and population or community dynamics.

In the following, how the partitioning of the energy ingested by an individual can be modelled within the framework of PSP models will be first discussed and thereafter how the functional forms of the interactions between the individual and its environment (food resources, predators) can be derived will be considered.

\section{MODELLING INDIVIDUAL ENERGETICS}

Studying the partitioning of ingested energy was a prime focus of fish energetics research in particular between 1970 and 1990 (Webb, 1978; Brett, 1979; 
Elliott, 1994; Jobling, 2002). A basic energy-balance (or energy-budget) model could be described by: $Q_{\mathrm{R}}-\left[Q_{\mathrm{F}}+Q_{\mathrm{B}}\right]=Q_{\mathrm{S}}+Q_{\mathrm{L}}+Q_{\mathrm{SDA}}+Q_{\mathrm{G}}+Q_{\mathrm{P}}$, where $Q_{\mathrm{R}}$ is food consumed, $Q_{\mathrm{F}}$ is faecal loss, $Q_{\mathrm{B}}$ is excretory loss, $Q_{\mathrm{S}}$ is standard metabolism, $Q_{\mathrm{L}}$ is locomotory (activity) cost, $Q_{\mathrm{SDA}}$ is apparent specific dynamic action, $Q_{\mathrm{G}}$ is growth in somatic tissue and $Q_{\mathrm{P}}$ is reproductive cost for gamete synthesis (Webb, 1978). PSP models that have focused on the dynamics of fish populations include all these components of individual energetics. In the general literature on PSP models, two principal types of energy-budget models have been used: (1) models where energy allocation to gonad growth takes precedence, and the remaining energy is used for somatic growth and metabolism [Fig. 1(a)] and (2) net-production models where costs for metabolism $\left(Q_{\mathrm{S}}, Q_{\mathrm{L}}\right.$ and $Q_{\mathrm{SDA}}$ above) are first paid for and the remaining energy is split between somatic and gonad growth [Fig. 1(b)] (Kooijman \& Metz, 1984; Persson et al., 1998). Conclusive experimental support for any of the energy-budget models is largely lacking at present, and there is therefore a strong need for experimental studies on this topic.

Using a net-production approach to model individual energetics, Persson et al. (1998) assumed that the individual $(i)$ state could be described by two physiological variables, irreversible and reversible mass. In irreversible mass, $x$, compounds like bones and organs, which cannot be starved away by the consumer are included. Reversible mass, $y$, is made up of energy reserves such as fat, muscle tissue but also gonads. The energy reserves may be used to cover basic metabolism during starvation. The main reason for combining energy reserves and gonads into one component, reversible mass, was to simplify the model formulation.

It was assumed that there exists a maximal ratio of reversible mass to irreversible mass, which is different for juveniles and adults. The ratio for juveniles and adults was denoted by $q_{\mathrm{j}}$ and $q_{\mathrm{a}}$, respectively (Fig. 2). As long as it does not starve, a juvenile individual will always have this maximum ratio of reversible $v$. irreversible mass. The allocation function differs for adults as they in addition to fat reserves also allocate mass to gonads. The maximum amount of reversible mass for an adult individual is therefore proportionally larger and equals $q_{\mathrm{a}} x$ (Fig. 2). Maturation is assumed to occur on reaching a size threshold $x=x_{\mathrm{f}}$.

If energy intake is larger than the costs of metabolism, the surplus energy is invested in growth. It is assumed that a fraction of the surplus energy is allocated to growth in irreversible mass and the rest into growth of reversible mass. The allocation rule was described such that the mature individuals will approach the boundary $q_{\mathrm{a}} x$ but seldom reach it (Persson et al., 1998). If the net energy intake is negative, the individual starves and reversible mass (but

(a)

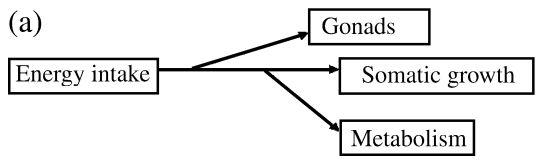

(b)

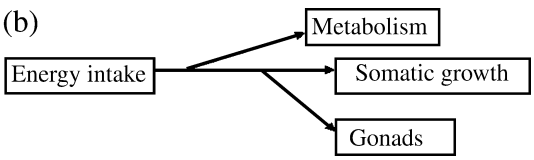

FIG. 1. Flow diagrams of the two basic types of energy-budget models. (a) The Kooijman \& Metz (1984) model assumes that energy is first split between reproduction and other processes whereas (b) netproduction models assume that the costs for metabolism are first paid before energy is split between gonad and somatic growth. 


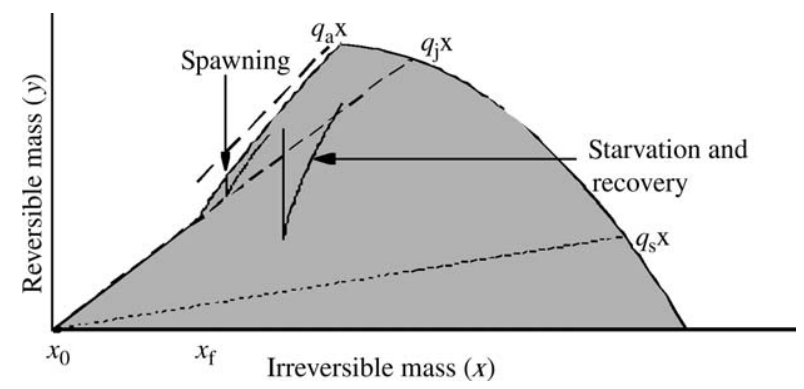

FIG. 2. Schematic representation of the dynamics in irreversible mass and reversible mass in the model of Persson et al. (1998). The consumer is assumed to be born with an irreversible mass of $x_{0}$ and a reversible mass of $q_{\mathrm{j}} x_{0}$ and will grow in mass along the line $y=q_{\mathrm{j}} x$ as long as it does not starve. When reaching maturity (at irreversible mass $x_{\mathrm{f}}$ ), it increases its maximum amount of reversible mass to $q_{\mathrm{a}} x$. When the individual spawns, reversible mass drops to $q_{\mathrm{j}} x$. After spawning the individual allocates mass according to an overall rule for energy partitioning that is targeted to restoring the maximal ratio, $q_{\mathrm{a}}$, between reversible and irreversible mass. When starving, the individual only decreases in reversible mass, while during recovery after a starvation period, it allocates mass preferentially to reversible mass. Below the line $y=q_{\mathrm{s}} x$, the individual starts to die of starvation. The individual may be positioned anywhere in the $(x, y)$ space $(\square)$ within the limits set by $y=q_{\mathrm{j}} x$ (when $x<x_{\mathrm{f}}$ ), $y=q_{\mathrm{a}} x$ (when $x>x_{\mathrm{f}}$ ), the $y=0$ axis and to the right by the maintenance limit set by the maximum resource density.

not irreversible mass) decreases (Fig. 2). It is assumed that the individual can stand a certain amount of starvation, down to the point when reversible mass equals $q_{\mathrm{s}} x$ before its death rate increases due to starvation. The rate of starving to death when the reversible mass is below $q_{\mathrm{s}} x$ is assumed to increase with the proportion irreversible mass:reversible mass.

PSP models can be formulated both for situations with continuous reproduction as well as for situations when reproduction is pulsed due to, for example, a seasonal environment (De Roos et al., 1992; Persson et al., 1998). In the model that is graphically illustrated in Fig. 2, reproduction is assumed to take place discretely at the start of the growing season. As they allocate mass to gonads, adult individuals have a higher maximum reversible mass than juveniles, as explained above. The amount of reversible mass exceeding $q_{\mathrm{j}} x$ at the end of the growing season is used for reproduction the next season. At the same time, the parent's reversible mass is reduced to $q_{\mathrm{j}} x$ (Fig. 2). If a mature individual's reversible mass is $<q_{\mathrm{j}} x$ at the end of the growing season, it will not reproduce.

The above model formulation has been described in some detail to give an overview of how an individual model for energy channelling of ingested energy can be developed. Some parts of this formulation have been based on experimental evidence, whereas other parts at present have only limited empirical support. The latter results from a lack of information about significant parts of the energy channelling in fishes, despite the fact that a large number of studies on fish energetics have been carried out (Webb, 1978; Brett, 1995; Jobling, 2002). In particular, the modelling of starvation could be substantially improved by further experimental studies. Some modifications of the energy channelling assumptions in Fig. 2 have also been tested in some studies. For example, with the energy channelling shown in Fig. 2, gonad tissue is used up before fat reserves when the energy balance is negative. It is, however, 
known that energy reserves may actually be used to build up gonad tissue when the energy balance is negative (MacKinnon, 1973). Correspondingly, van de Wolfshaar (2006) used an energy-budget model where fat reserves were metabolized before gonad mass when studying the effects of a winter season on the dynamics of a consumer resource model.

\section{DEDUCING FOOD-DEPENDENT GATHERING FUNCTIONS: COHORT CYCLES}

To describe of how ingested energy is channelled to different activities, individual-level formulations to determine the size dependency of food intake as a function of consumer size are needed. Like predator-prey models in general, the relation between capture rate and prey density for a consumer of size $w$ can be described by a Holling II function response (Mittelbach, 1981; Persson, 1987; Byström \& Gàrcía-Berthóu, 1999; Hjelm \& Persson, 2001): $C(w, R)=a(w) R[1+a(w) h(w) R]^{-1}$, where $a(w)$ is the attack rate, $h(w)$ is the handling time and $R$ is the resource density. For a fixed prey size, Persson et al. (1998) suggested that the attack rate $a(w)$ should be a hump-shaped function of predator size, where the initial increase of the foraging capacity with predator size is due to an increase in visual acuity and locomotor ability, both of which will affect the encounter with prey (Peters, 1983; Persson, 1987; Noakes \& Godin, 1988; Werner, 1988). The decreasing part of the function can be related to a decrease in rod density and hence the capacity to discern small prey, and a decreased ability to make fine-tuned manoeuvres (Breck \& Gitter, 1983; Persson, 1987; Noakes \& Godin, 1988). One equation describing a hump-shaped relationship between attack rate (volume or area searched per unit of time) and body mass is:

$$
a(w)=A\left[w w_{\mathrm{o}}^{-1} e^{\left(1-w w_{\mathrm{o}}^{-1}\right)}\right]^{\alpha}
$$

where $A$ is the maximum attack rate rate, $w_{\mathrm{o}}$ the body size at which the maximum rate is achieved and $\alpha$ a size-scaling exponent. Experimental studies of several fish species show that the size dependency of the attack rate for a constant prey size is well described by equation 1 (Hjelm \& Persson, 2001; Persson \& Brönmark, 2002a, b; Byström \& Andersson, 2005) (Fig. 3).

Handling time is also a function of body size. Different forms for the relationship between handling time and body size have been used (Persson et al., 1998; Claessen et al., 2000), where the most commonly used function assumes handling capacity ( $h$, mass per unit time) to decrease monotonically with body mass following a power function: $h=b_{1} w^{b_{2}}$, where $b_{1}$ and $b_{2}$ are constants (Claessen et al., 2000). The derivation of this expression is based on the assertion that maximum intake rates are mainly determined by digestive constraints and hence most of the time spent on processing resources is due to digestion as opposed to handling of prey per se (Claessen et al., 2000).

To complete the individual description, metabolic costs need to be modelled. For this, a power relationship between metabolic costs and body mass has generally been used (Peters, 1983; Calder, 1984; Werner, 1988; Persson et al., 1998; Kooijman, 2000). 


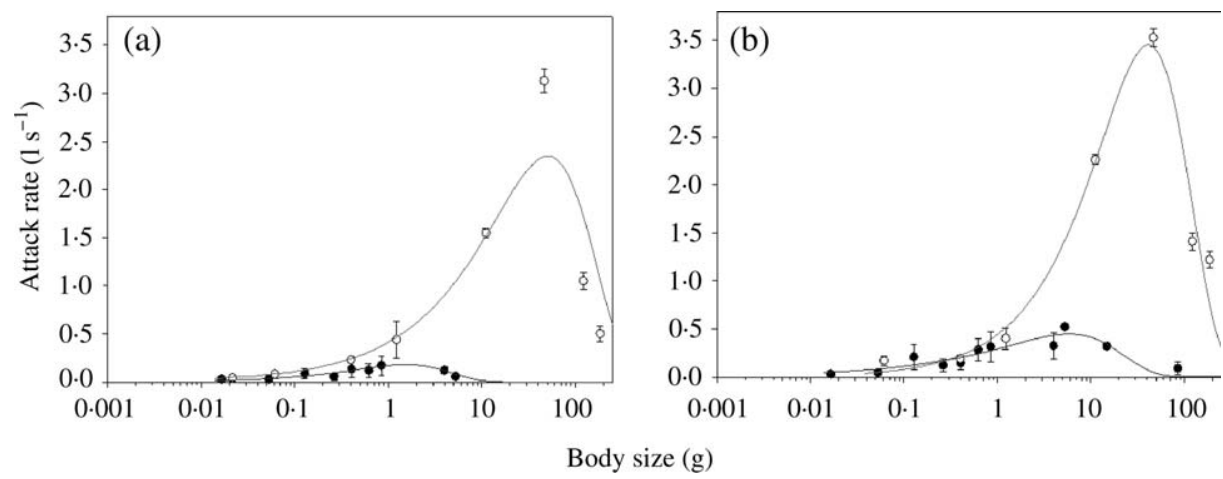

FIG. 3. Mean \pm s.E. attack rates of roach $(\bigcirc)$ and perch $(\mathbf{O})$ as a function of their size (mass) on (a) $0 \cdot 5$ and (b) 1.0 mm Daphnia sp. The functions were fitted to data using equation 1. Data from Byström \& Gàrcía-Berthoú (1999) and Hjelm \& Persson (2001).

Given the size dependencies of foraging rate (attack rate and handling time) and metabolic costs, the lowest resource density, which is just sufficient to cover maintenance requirements (gains $=$ costs) can be calculated for differentsized individuals (Persson et al., 1998). Extensive analysis of the PSP model for the interaction between a planktivorous consumer roach Rutilus rutilus (L.) and its zooplankton resource (Daphnia sp.) has revealed that the shape of the relationship between this critical resource density $(C R D)$ and body size can be used to predict population dynamics (Persson et al., 1998). If $C R D$ increases monotonically with body size, small individuals are always competitively superior to larger individuals. In this case, cycles driven by recruiting cohorts will result where a large newborn cohort will depress the shared resource and out-compete larger (older) cohorts. When this large and dominating cohort matures it will give rise to another strong cohort, which will outcompete its predecessors. These inter-cohort competition driven cycles are thereby characterized by a cycle length that equals generation time. If $C R D$ is relatively independent of body size, differently sized cohorts are about equal in competitive ability, which will prevent any cohort dominating, leading to equilibrium conditions. Finally, if $C R D$ first decreases with body size, cycles reappear. These cycles are, however, driven by older juveniles that by depressing the resource may prevent less competitive newborn cohorts to enter the system (Persson et al., 1998).

Given that metabolic requirements roughly scale with $w^{0.75}$ for most fish species, the shape of the $C R D$-body size curve is to a large extent determined by the size-scaling parameter $\alpha$. Persson et al. (1998) found a monotonically increasing $C R D$-body size curve for $\alpha<0.9$. Experimental data on sizedependent attack rates are known for six freshwater fish species and for all these species the size scaling of the attack rate is such that $C R D$ indeed increases monotonically with body size (Table I). Present experimental data on size-dependent attack rates in fishes therefore predict that inter-cohort competition is expected to result in cycles driven by recruiting young-of-the-year (YOY) cohorts. Time series for at least four freshwater fishes species [roach, bream Abramis brama (L.), vendace Coregonus albula (L.) and yellow perch Perca flavescens (Mitchill)] do provide evidence for cycles, and for two of these 
TABLE I. Size scaling of attack rate $(\alpha)$ and form of the relationship between the critical resource density and body size for six fish species feeding on zooplankton

\begin{tabular}{|c|c|c|c|c|}
\hline Species & & $\begin{array}{l}\text { Size } \\
\text { scaling }\end{array}$ & $\begin{array}{c}\text { Critical resource } \\
\text { density }\end{array}$ & Source \\
\hline Bluegill & Lepomis macrochirus & 0.66 & $\begin{array}{l}\text { Monotonically } \\
\text { increasing }\end{array}$ & Mittelbach (1981) \\
\hline Roach & Rutilus rutilus & $0 \cdot 5$ & $\begin{array}{l}\text { Monotonically } \\
\text { increasing }\end{array}$ & Hjelm \& Persson (2001) \\
\hline Bream & Abramis brama & $0 \cdot 67$ & $\begin{array}{l}\text { Monotonically } \\
\text { increasing }\end{array}$ & $\begin{array}{l}\text { Persson \& } \\
\quad \text { Brönmark (2002a) }\end{array}$ \\
\hline Perch & Perca fluviatilis & $0 \cdot 62$ & $\begin{array}{l}\text { Monotonically } \\
\text { increasing }\end{array}$ & $\begin{array}{l}\text { Byström \& } \\
\text { Gàrcía-Berthóu (1999) }\end{array}$ \\
\hline Pikeperch & Sander lucioperca & $0 \cdot 47$ & $\begin{array}{l}\text { Monotonically } \\
\text { increasing }\end{array}$ & $\begin{array}{l}\text { Persson \& } \\
\quad \text { Brönmark }(2002 b)\end{array}$ \\
\hline Arctic char & Salvelinus alpinus & $0 \cdot 65$ & $\begin{array}{l}\text { Monotonically } \\
\text { increasing }\end{array}$ & $\begin{array}{l}\text { Byström \& } \\
\quad \text { Andersson (2005) }\end{array}$ \\
\hline
\end{tabular}

species (roach and cisco) it has also been clarified that the cycles are recruitdriven cycles (Hamrin \& Persson, 1986; De Roos \& Persson, 2001).

The observed cycle length found in fishes generally varies from 2 to 4 years (Aass, 1972; Hamrin \& Persson, 1986; Townsend et al., 1990; Helminen et al., 1993; Lammens, 2002). It has also been observed that the regularity of these cycles decreases with cycle length (Hamrin \& Persson, 1986). Correspondingly, Huusko \& Hyvarinen (2005) found that increased harvesting mortality and thereby decreased cycle length in a vendace population resulted in a more regular cycle. The decrease in regularity of cohort cycles with increasing cycle length is not something that is expected based on the deterministic PSP models. It might therefore be argued that stochastic influences should become more prominent for longer cycles. Indeed, van Kooten et al. (2004) showed that size divergence in cohorts could occur as a result of stochasticity via local interactions. The stochasticity, in turn, resulted in longer cycles that became much less regular, whereas the regularity of shorter 2 year cycles was unaffected by stochasticity.

The yellow perch population studied by Sanderson et al. (1999) stands out as an exception to the rule that longer cycles tend to be less regular. The cycle length of this yellow perch population amounted to 7 years, but the cycle was still surprisingly regular. One possible explanation for the regularity of the cycle in yellow perch relates to that although the cycle was driven by inter-cohort competition (Persson et al., 2004a), cannibalism is also present in yellow perch. It can hence be suggested that a dominating cohort through cannibalism may prevent the recruitment of new cohorts until this dominating cohort matures and thereby increase the regularity of the cycle.

As considered above, existing data on size-dependent food-gathering capacity in fishes suggest that smaller fish individuals in general should be competitively superior leading to recruit-driven cohort cycles. This argument is based on the assumption that competition for resources is exploitative. In species 
where interference and territoriality are present as in many salmonids, larger individuals may, however, be overall superior competitors. Although not formally analysed, interference can therefore be hypothesized to have the potential to stabilize cohort cycles or even lead to cycles driven by competitively superior larger individuals (Persson et al., 1998).

\section{DEDUCING FOOD-DEPENDENT GATHERING FUNCTIONS: SIZE-STRUCTURED PREDATOR AND SIZE-STRUCTURED PREY}

A fundamental feature of predator-prey interactions among fishes is their sizedependent nature (Werner, 1977; Juanes, 2003). So far, this size dependency has in this paper been restricted to predator size (Fig. 3). There exist in the fish literature a number of attempts to address the functional relationships between sizestructured predators and size-structured prey (Rice et al., 1997; Dong \& DeAngelis, 1998; Claessen et al., 2000; Juanes, 2003). In general, two boundaries of interest have been discussed. First, there exists an upper boundary above which the escape ability of victims or the gape constraints in the predator prohibit capture (Christensen, 1996; Claessen et al., 2000; Juanes, 2003). Second, there exists a lower boundary beyond which the predator will not encounter the prey because of limitations in the ability to see small prey (Lundwall et al., 1999; Claessen et al., 2000). Within these boundaries, there also exists an optimum prey:predator size ratio where the attack rate of a predator of a specific size is at its maximum. Functions to describe these three size-dependent predator-prey relationships can be found in Rice et al. (1997), Claessen et al. (2000) and Persson et al. (2004a). Claessen et al. (2000) used a 'tent' function, shown graphically in Fig. 4, to describe the relation between predator and prey sizes and the attack rate over the entire range of size combinations between the upper and lower boundary to the prey:predator size ratio.

Both predator and prey will grow over time. Given the size-dependent attack rate, the attack rate of differently sized fishes will therefore change as a result of both their own size and the growth of their prey. How the attack rate on YOY perch Perca fluviatilis L. by a 1 year-old perch and a perch individual having a size of $190 \mathrm{~mm}$ at the start of the season change over time is shown in Fig. 5. The attack rate of a 1 year-old perch is at its maximum at the hatching size of YOY perch, to thereafter decrease to zero over time. In contrast, the attack rate of a $190 \mathrm{~mm}$ perch is first zero, to thereafter increase, to finally decrease (Fig. 5). The different time trajectories for the attack rates of differently sized perch have three implications of interest. First, prey may evade growing predators by growing faster in length than their predators (Wilbur, 1988). Second, there may exist a size refuge for small prey below which they are not encountered by the predator. Third, differently sized predators exhibit a temporal separation in maximum mortality impact on and energy intake from growing prey. This means that smaller predators can potentially deplete the prey resource and thereby out-compete larger predators before the latter can obtain access to the shared prey. In contrast, the expected gain of consuming a prey is smaller for smaller predators as they eat prey at younger ages. 


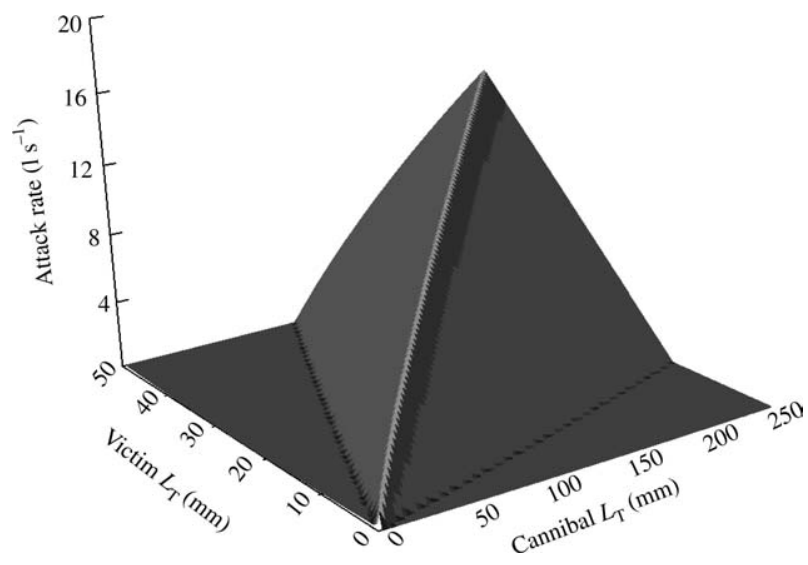

FIG. 4. Three-dimensional plot of the cannibalistic attack rate as a function of cannibal and victim total length based on the tent function described in Claessen et al. (2000) including the minimum, optimal and maximum victim:cannibal size ratios.

\section{INTRASPECIFIC INTERACTIONS: CANNIBALISM}

Most studies on size-dependent predator-prey interactions have focused on the implications of the upper size refuge (Hambright, 1991; Brönmark et al., 1995; Rice et al., 1997). Studies on intraspecific predator-prey (cannibalistic) interactions, however, show that the lower size boundary may have a larger influence on population dynamics of cannibalistic fish populations than the upper size boundary (Claessen et al., 2002). Persson et al. (2004b) showed that the population dynamics of different cannibalistic species could be predicted based on their lower boundary for cannibalism. The impact of the lower size boundary

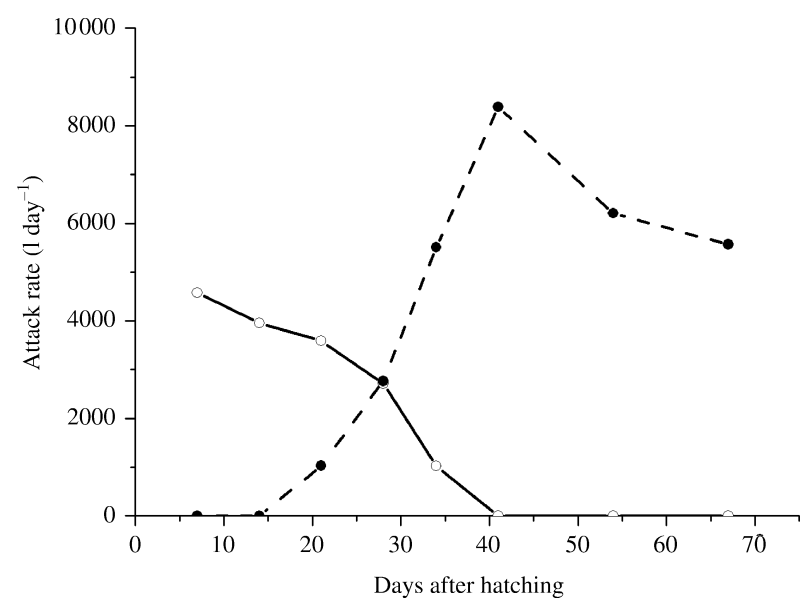

FIG. 5. Changes in attack rate of growing 1 year-old and older perch with a total length of $50(\bigcirc)$ and 190 (O) at the start of the summer, respectively, on growing young-of the-year perch. The changes in attack rate are computed using the cannibalistic attack function shown in Fig. 4 on the basis of the observed growth rates of the different size classes of perch (data from Persson et al., 2004a). 
results from the fact that cannibals and victims in addition to the predator-prey interaction are also involved in competition for shared resources (zooplankton and macroinvertebrates). If the lower size boundary is too high, victims may out-compete their cannibals before victims reach a size where they become susceptible to cannibalism. As a result, the population dynamics essentially becomes driven by cohort competition despite the presence of some cannibalism. A suggested example of a species showing this type of population dynamics is yellow perch (Sanderson et al., 1999). On the other hand, cannibals having a lower minimum victim-cannibal size boundary, such as pike Esox lucius L., show rather stable dynamics where size distributions vary less over time (Persson et al., $2004 b$, 2006). In this case, cannibals presumably prevent the negative competitive impact of strong recruiting cohorts by imposing a high mortality on them early in life. Such cannibals control the competition from recruiting individuals by killing them. Perca fluviatilis having an intermediate minimum victim-cannibal size ratio has been shown to exhibit a mixture of dynamics shifting between cohort competition and cannibal control (Persson et al., 2003). Pike has been classified as an obligate piscivore, whereas perch has been classified as a facultative piscivore (Mittelbach \& Persson, 1998). Based on the different population dynamics of these two species, it can be hypothesized that the piscivorous guild classified by Mittelbach \& Persson (1998) as obligate piscivores should most probably be characterized by cannibal-controlled dynamics, whereas the mixed dynamics observed in perch is most likely found among facultative piscivores.

Studies of energy gain from cannibalism have in both theoretical and empirical studies revealed that control of victims by cannibals and high energy gain from cannibalism do not occur simultaneously (Claessen et al., 2000; Persson et al., 2000). This results from the fact that in populations, in which cannibals impose a high mortality on victims, mortality occurs very early in the life period of victims when they only represent small amounts of energy. Instead, the main energy gain for such cannibals comes from the shared resource (zooplankton and macroinvertebrates). In contrast, when cannibals do not control competing victims by killing them at young ages or small sizes, surviving cannibals may gain large amounts of energy from cannibalism as victims overall survive to larger sizes where they represent larger energy packages for the cannibals. During these periods without cannibal control, surviving cannibals may therefore accelerate rapidly in growth reaching sizes three times as large compared to periods, in which cannibals control victims by imposing a high mortality (Persson et al., 2000).

\section{INTERSPECIFIC INTERACTIONS}

Equipped with the functional relationships between size-structured consumers and resources and between size-structured predators and size-structured consumers, it is in principle straightforward to study interspecific interactions between size-structured populations. While the coverage of cohort competition and cannibalism has had its focus on the dynamical consequences of size variation and food-dependent growth, the coverage of multispecies interactions in the present paper will focus on the effects of size-structure and food-dependent development on community structure. 


\section{Mixed predation-competition interactions}

A general feature of interactions among fish species is that not only does the intensity of competitive interactions varies with size, but also that the interactions shift between competitive and predatory during ontogeny (Olson et al., 1995; Byström et al., 1998; Mittelbach \& Persson, 1998). Interactions between fish populations will therefore typically be a mixture of interactions where small stages of a piscivorous species may suffer from competition with planktivorous and benthivorous species, whereas large stages of the piscivorous species prey on these planktivorous and benthivorous species (Larkin \& Smith, 1954; Persson, 1988; Byström et al., 1998). In a more general ecological context such a mixed interaction represents a life history omnivory system (Polis et al., 1996). Previous modelling studies of omnivorous systems with a top predator, an intermediate consumer and a shared resource show that coexistence between top predator and intermediate consumer is possible at intermediate productivities (Diehl \& Feissel, 2000; Mylius et al., 2001). In contrast, recent modelling of omnivorous systems with size-structure and food-dependent growth in predator and intermediate consumer show that food-dependent growth will strongly demote the possibility for coexistence between top predator and intermediate consumer at any productivity (van de Wolfshaar et al., 2006).

Thus, size-structured theory predicts that coexistence between top predators (piscivores) and intermediate consumers (plankivores and benthivores) is unlikely in tightly interlinked omnivorous systems. This naturally raises a number of questions for fish ecologists as the coexistence of piscivorous fish species with planktivorous and benthivorous fish species is observed. It can be argued that resource partitioning among several basal resources (zooplankton and macroinvertebrates) may promote coexistence. This mechanism, however, is only likely to be important when resources are exclusive for top predators and intermediate consumers. Cannibalism in piscivorous species may to some extent promote coexistence between top predators and intermediate consumers, but it is unclear whether this may explain the coexistence of piscivorous and forage fishes in general (van de Wolfshaar et al., 2006). The interaction between the facultative piscivore perch and the intermediate consumer roach represents one example of a tightly coupled omnivorous system that according to theory should not be able to coexist (van de Wolfshaar et al., 2006). Comparative data from different lakes actually show that the combination of only perch and roach in the fish community does not occur as roach only co-occur with perch in the presence of other piscivores like pike (Sumari, 1971). It can therefore be suggested that the theoretical predictions of a low probability of coexistence between facultative piscivores and intermediate consumers in omnivorous systems are essentially correct, and that the presence of other, obligate piscivores feeding on the facultative piscivore is a necessary condition for the coexistence of the facultative piscivore with the intermediate consumer.

\section{Food-dependent growth and catastrophic collapses}

The example with mixed competition and predation showed that food-dependent growth in size-structured populations of fishes might demote the coexistence between planktivorous and benthivorous species and their predators. Food-dependent 
growth in combination with size-selective predation may also make fish populations more prone to catastrophic collapses than populations not exhibiting sizestructure and food-dependent growth. In a tritrophic model with a resource, a size-structured consumer and a non size-structured predator, De Roos \& Persson (2002) showed that harvesting of the top predator could lead to a catastrophic collapse of the top predator. In the particular example studied, the top predator fed selectively on the smallest size range of the consumer population. The catastrophic behaviour of the system resulted from the fact that predation by the top predator on the smallest consumers actually increased the biomass of these smallest consumers. Conversely, decreased predation (due to harvesting) led to a decrease in the biomass of the smallest consumers leading to a collapse of the top predator at some threshold level. The mechanism behind this positive feedback of the top predator on its own prey results from predation on small consumers causing an increase in individual growth of remaining juvenile consumers leading to an overcompensating increase in adult biomass and population fecundity. The key to understanding the appearance of the positive feedback and catastrophic behaviour thus lies in the food-dependent growth in the consumer. If, in contrast, a constant length-age relationship is assumed and hence if higher resource levels do not increase individual growth, adult biomass and population fecundity decrease monotonically with increasing mortality on the small consumers (De Roos \& Persson, 2002), prohibiting the catastrophic behaviour to occur.

Although it was assumed that the top predator was unstructured in the above example, the presence of size structure in the top predator does not qualitatively change the catastrophic propensity of the system. In addition it has been shown that the catastrophic behaviour also results from positive size selection in the predator (De Roos \& Persson, 2005). Overall, predator-induced shifts in the size distribution of consumer populations thus have major ramifications for community structure. The catastrophic behaviour resulting from food-dependent growth and size-selective predation has been forwarded as one explanation for the collapse and lack of recovery that has been observed in stocks of marine top predators like the North Atlantic cod Gadus morhua L. (Carscadden et al., 2001; De Roos \& Persson, 2002, 2005).

\section{DETAILED PREDICTION ABOUT SPECIFIC SYSTEMS $V S$. BROAD PREDICTIONS ABOUT MULTISPECIES SYSTEMS}

How the framework of PSP models allows for an analysis of the different types of dynamics exhibited by fish populations in both single and multispecies systems has been considered: (a) How PSP models can be used for detailed quantitative predictions with the aim of unravelling the precise mechanisms behind observed dynamics in a particular system, and (b) the potential to analyse many species systems such food webs using PSP models are now discussed.

\section{Individual-based formulations for quantitative predictions and detailed mechanisms}

PSP models allow for a more extensive testing of model predictions against empirical data than most contemporary population models, which can be related to two main properties of PSP models. First, comparisons between 
model predictions and empirical data have a higher discriminative power as most parameter estimates are derived independently from the target data set and assumptions and parameter values that are required as input exclusively pertain to individual-level processes. De Roos \& Persson (2001) were, for example, able to predict the population cycle of roach in an English lake (Alderfen Broad) based on experimental laboratory data on consumption rates and metabolism in roach. Second, in contrast to non-structured or stage-based models, predictions of PSP models include both population-level predictions (overall dynamics, cycle length and amplitude) as well as individual-level predictions (growth, fecundity and mortality). Moreover, the predicted individuallevel processes are to a large extent shaped by population feedbacks and hence rather independent of the assumptions that the models are based upon. For the Alderfen Broad example, De Roos \& Persson (2001) were able to quantitatively predict the growth rate of weak and strong year classes in the 2 year cycle of roach in this lake.

PSP models are also well suited for the analysis of within-generation ecological data in a more quantitative sense to unravel mechanisms driving the dynamics of populations. When confronting the predictions of a model for a cannibalistic perch population with empirical data, Claessen et al. (2000) found a number of qualitative discrepancies. One of these discrepancies was that the model predicted accelerated growth of perch on a cannibalistic diet, while they were feeding on a single year class of victims over consecutive years. In contrast, field data showed that cannibals accelerated in growth by feeding on subsequent YOY age classes (Persson et al., 2004a). A within-season modelling study showed that empirically observed diets of different size classes of perch were correctly predicted by a detailed PSP model, which accounted for cannibalism as well as foraging on zooplankton and macroinvertebrates. Moreover, it could be shown that acceleration in growth as empirically observed could be explained by feeding on subsequent year classes of YOY perch and that growth acceleration did not require 'surfing' on one growing year class over several years (Fig. 6). Finally, the within-season modelling revealed that the original model (Claessen et al., 2000) did not correctly handle a critical element of the dynamics: strong competitive interactions between YOY and 1 year-old perch (Persson et al., 2004a). Thus, the within-season modelling led to a modified model of perch population dynamics that better resembled the cannibalistic dynamics observed in the field (Persson et al., 2003).

\section{Individual-based formulations for general mechanisms}

A basic and seemingly unsolvable dilemma in the formulation and the use of models has been to simultaneously achieve generality, realism and precision (Levins, 1966). PSP models have so far been used to explore the dynamics of size-structured communities up to a complexity level of two size-structured populations and two non-structured resource populations (van de Wolfshaar, 2006). Due to the parameter richness of these PSP models, it is questionable whether a general and mechanistic understanding of the community dynamics can be achieved if more species are added. At the same time, ecological systems most often consist of many species. 


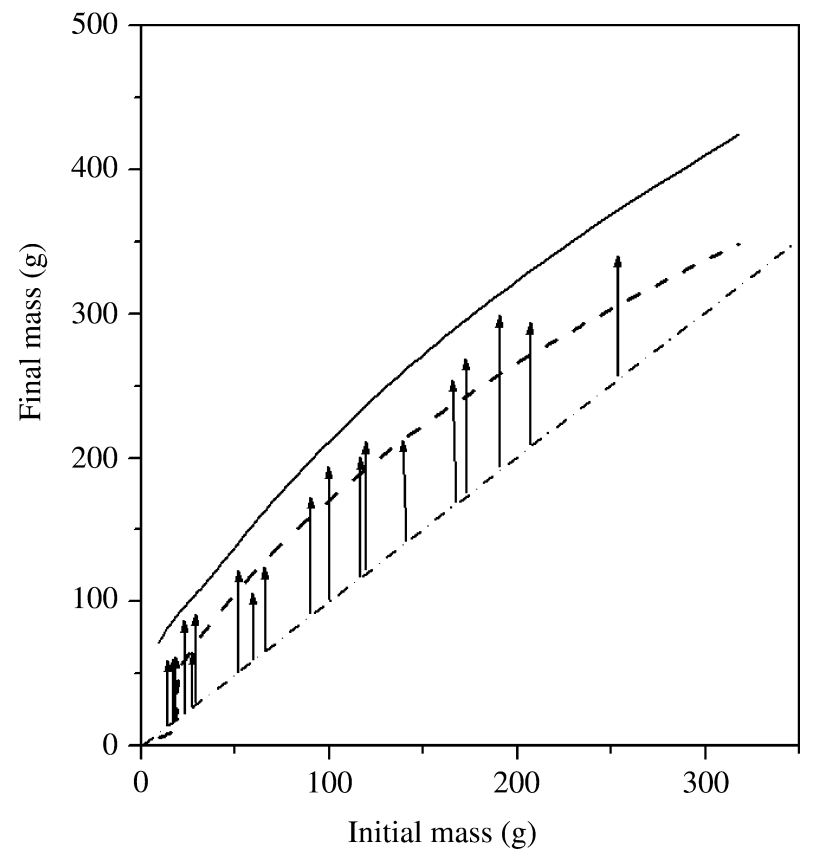

FIG. 6. Predicted ultimate mass that perch individuals with different initial sizes can attain at the end of the growing season depending on their diet composition. Predictions were generated by a detailed PSP model that accounts for cannibalism as well as foraging on zooplankton and macroinvertebrates (Persson et al., 2004a). Lines represent predictions when perch were assumed to feed on YOY perch only (--:) or macroinvertebrates, zooplankton and YOY perch (-). - - , the total mass of an individual that just maintains its mass over the growth season $\left(y=q_{\mathrm{j}} x\right)$. Inserted vectors are observed mass changes (means for each age cohort) based on data in Persson et al. (2004a).

Basically, there are two routes out of this dilemma, the choice of which depends on the question addressed. First, it can be argued that despite a high number of species present, there are a restricted set of species that are dynamically important, and by focusing the analysis on these species something about the dynamics of these species per se can be determined as well as the dynamics of the system overall. An example of this is the study of roach in Alderfen Broad, where Cryer et al. (1986) and Townsend et al. (1990) showed that the pattern in zooplankton dynamics between years could be explained by the cohort cycle of roach despite the presence of other fish species in the system. An alternative approach is to try to reduce the complexity of PSP models, while preserving the essence of their individual-based formulation. Recently, A. M. De Roos, T. Schellekens, D. Claessen, T. van Kooten \& L. Persson (unpubl. data), have developed a structured biomass approach for size-structured populations analogous to the bioenergetics population model proposed by Yodzis \& Innes (1992) for non-structured populations. In its simplest form, the structured biomass model is formulated in terms of three ordinary differential equations (for adults, juveniles and resources) but still accounts for food-dependent development (in juveniles) and fecundity (in adults). The structured biomass community model is derived from a basic PSP model in such a way that there 
is complete correspondence between all equilibria predicted by the two models. Analyses show that the catastrophic behaviour observed in size-selective predator-consumer interactions are also predicted by the more aggregated biomass community model (A. M. De Roos, T. Schellekens, D. Claessen, T. van Kooten \& L. Persson, unpubl. data). This more aggregated model can be exploited to investigate the importance of size-structured-induced shifts in community structure in more specious systems.

The aim of this review has been to show how PSP models can be a useful tool for analysing the dynamics of size-structured populations such as fish populations. In particular, the explicit handling of individual-level properties makes these models most relevant for fish populations given the substantial knowledge about individual-level energetics in fishes. More experimental information about, for example, starvation processes, is needed to improve the validity of model assumptions.

During the last decade the understanding of the dynamics of inter-cohort competition and cannibalism has increased to a level where population dynamics can be linked to individual-level life-history characteristics. Qualitatively new knowledge has also been generated about the influence of size-structured dynamics and food-dependent growth on community structure. In this area, there is still room for substantial research on how life-history characteristics of interacting species influence community dynamics and structure. A challenge is also to develop simplified models that allow the analysis of a more complex specious system but at the same time preserve those features of the individuallevel formulations that have proven to be crucial for the dynamics of interacting, size-structured populations. The most prominent feature in this respect is the food dependence in individual growth and development, which is lacking from classical, unstructured population-level models of community dynamics. Finally, two major research areas for the future that have only recently been addressed in the context of size-structured dynamics can be pointed out, namely harvesting and evolutionary dynamics in the presence of ecological feedbacks (De Roos et al., 2006).

The research based on which this overview was written has been supported by the Swedish Research Council and the Swedish Research Council for Environment, Agricultural Sciences and Spatial Planning to L. Persson and the Netherlands Organization for Scientific Research to A. M. De Roos.

\section{References}

Aass, P. (1972). Age determination and year class fluctuations of ciscoe (Coregonus albula) in the Mjösa hydroelectric reservoire. Report Institute of Freshwater Research, Drottningholm 52, 4-21.

Backiel, T. \& Le Cren, D. E. (1978). Some density relationships for fish population parameters. In Ecology of Freshwater Production (Gerking, S. D., ed.), pp. 279-302. London: Blackwell Scientific Publications.

Beverton, R. J. \& Holt, S. J. (1957, reprinted 1993). On the Dynamics of Exploited Fish Populations. London: Chapman \& Hall.

Breck, J. E. \& Gitter, M. J. (1983). Effect of fish size on the reactive distance of bluegill (Lepomis macrochirus) sunfish. Canadian Journal of Fisheries and Aquatic Sciences 40, 162-167. 
Brett, J. R. (1979). Environmental factors and growth. In Fish Physiology, Vol. VIII (Hoar, W. S., Randall, R. J. \& Brett, J. R., eds), pp. 599-675. London: Academic Press.

Brett, J. R. (1995). Energetics. In Physiological Ecology of Pacific Salmon (Groot, C. L., Margolis, L. \& Clarke, W. C., eds), pp. 2-68. Vancouver: University of British Columbia Press.

Brönmark, C., Paszkowksi, C. A., Tonn, W. M. \& Hargeby, A. (1995). Predation as a determinant of size structure in populations of crucian carp (Carassius carassius) and tench (Tinca tinca). Ecology of Freshwater Fish 4, 85-92.

Byström, P. \& Andersson, J. (2005). Size-dependent foraging capacities and intercohort competition in an ontogenetic omnivore (Arctic char). Oikos 110, 523-536.

Byström, P. \& Gàrcía-Berthóu, E. (1999). Density dependent growth and size specific competitive interactions in young fish. Oikos 86, 217-232.

Byström, P., Persson, L. \& Wahlström, E. (1998). Competition between predator and prey - competitive juvenile bottlenecks in whole lake experiments. Ecology 79, 2153-2167.

Calder, W. A., III (1984). Size, Function and Life History. Cambridge: Harvard University Press.

Carscadden, J. E., Frank, K. T. \& Leggett, W. C. (2001). Ecosystem changes and the effects on capelin (Mallotus villosus), a major forage species. Canadian Journal of Fisheries and Aquatic Sciences 58, 73-85.

Caswell, H. \& John, A. M. (1992). From the individual to the population in demographic models. In Individual-based Models and Approaches in Ecology - Populations, Communities and Ecosystems (DeAngelis, D. L. \& Gross, L. J., eds), pp. 36-61. New York: Chapman \& Hall.

Christensen, B. (1996). Predator foraging capabilities and prey antipredator behaviours: pre- versus postcapture constraints on size-dependent predator-prey interactions. Oikos 76, 368-380.

Claessen, D. \& De Roos, A. M. (2003). Bistability in a size-structured population model of cannibalistic fish-a continuation study. Theoretical Population Biology 64, 49-65.

Claessen, D., De Roos, A. M. \& Persson, L. (2000). Dwarfs and giants: cannibalism and competition in size-structured populations. American Naturalist 155, 219-237.

Claessen, D., van Oss, C., De Roos, A. M. \& Persson, L. (2002). The impact of sizedependent predation on population dynamics and individual life history. Ecology 83, $1660-1675$.

Cryer, M., Peirson, G. \& Townsend, C. R. (1986). Reciprocal interactions between roach, Rutilus rutilus, and zooplankton in a small lake: prey dynamics and fish growth and recruitment. Limnology and Oceanography 31, 1022-1038.

De Roos, A. M. (1997). A gentle introduction to physiologically structured population models. In Structured-population Models in Marine, Terrestrial, and Freshwater Systems (Tuljapurkar, S. \& Caswell, H., eds), pp. 119-204. New York: Chapman \& Hall.

De Roos, A. M. \& Persson, L. (2001). Physiologically structured models - from versatile technique to ecological theory. Oikos 94, 51-71.

De Roos, A. M. \& Persson, L. (2002). Size-dependent processes promote the catastrophic collapse of top predators. Proceedings of the National Academy of Science USA 99, 12907-12912.

De Roos, A. M. \& Persson, L. (2005). The influence of individual growth and development on the structure of ecological communities. In Food Webs: Dynamic Food Webs - Multispecies Assemblages, Ecosystem Development and Environmental Change (de Ruiter, P. C., Wolters, V. \& Moore, J. C., eds), pp. 89-100. Amsterdam: Academic Press.

De Roos, A. M., Metz, J. A. J., Evers, E. \& Leipoldt, A. (1990). A size dependent predator-prey interaction: who pursues whom? Journal of Mathematical Biology 28, 609-643.

De Roos, A. M., Metz, J. A. J. \& Diekmann, O. (1992). Studying the dynamics of structured population models: a versatile technique and its application to Daphnia. American Naturalist 139, 123-147. 
De Roos, A. M., Boukal, D. \& Persson, L. (2006). Evolutionary regime shifts in age and size at maturation of exploited fish stocks. Proceedings of the Royal Society of London Series B 273, 1873-1880.

Diehl, S. \& Feissel, M. (2000). Effects of enrichment on three-level food chains with omnivory. American Naturalist 155, 200-218.

Diekmann, O., Gyllenberg, M. \& Metz, J. A. J. (2003). Steady state analysis of structured population models. Theoretical Population Biology 63, 309-338.

Dong, Q. \& DeAngelis, D. L. (1998). Consequences of cannibalism and competition for food in a smallmouth bass population: an individual-based modeling study. Transactions of the American Fisheries Society 127, 174-191.

Elliott, J. M. (1994). Quantitative Ecology and the Brown Trout. Oxford: Oxford University Press.

Hambright, K. D. (1991). Experimental analysis of prey selection by largemouth bass: role of predator mouth width and prey body depth. Transactions of the American Fisheries Society 112, 508-516.

Hamrin, S. F. \& Persson, L. (1986). Asymmetrical competition between age classes as a factor causing population oscillations in an obligate planktivorous fish species. Oikos 47, 223-232.

Helminen, H., Auvinen, H., Hirvonen, A., Sarvala, J. \& Toivonen, J. (1993). Year-class fluctuations of vendace (Coregonus albula) in Lake Pyhäjärvi, Southwest Finland, during 1971-1990. Canadian Journal of Fisheries and Aquatic Sciences 50, 925-931.

Hjelm, J. \& Persson, L. (2001). Size-dependent attack rate and handling capacity: intercohort competition in a zooplanktivorous fish. Oikos 95, 520-532.

Ivlev, V. S. (1961). Experimental Ecology of Feeding of Fishes. New Haven: Yale University Press.

Huusko, A. \& Hyvarinen, P. (2005). A high harvest rate induces a tendency to generation cycling in a freshwater fish population. Journal of Animal Ecology 74, 525-531.

Jobling, M. (2002). Environmental factors and rates of development and growth. In Handbook of Fish Biology and Fisheries, Vol. I (Hart, P. J. B. \& Renynold, J. D., eds), pp. 97-1222. Oxford: Blackwell Science.

Juanes, F. (2003). The allometry of cannibalism in piscivorous fishes. Canadian Journal of Fisheries and Aquatic Sciences 60, 594-602.

Kirkilionis, M. A., Diekmann, O., Lisser, B., Nool, M., Sommeijer, B. P. \& De Roos, A. M. (2001). Numerical continuation of equilibria of physiologically structured population models. I. Theory. Mathematical Models and Methods in Applied Science 11, 1101-1127.

Kitchell, J. F., Stewart, D. J. \& Weininger, D. (1977). Applications of a bioenergetics model to yellow perch (Perca flavescens) and walleye (Stizostedion vitreum vitreum). Journal of the Fisheries Research Board of Canada 34, 1922-1935.

Kooijman, S. A. L. M. (2000). Dynamic Energy Budgets in Biological Systems. Cambridge: Cambridge University Press.

Kooijman, S. A. L. M. \& Metz, J. A. J. (1984). On the dynamics of chemically stressed populations: the deduction of population consequences from effects on individuals. Ecotoxicology and Environmental Safety 8, 254-274.

van Kooten, T., De Roos, A. M. \& Persson, L. (2004). Local foraging and limited mobility: dynamics of a size-structured consumer population. Ecology 85, 1979-1991.

Lammens, E. H. R. R., Van Nes, E. H. \& Mooij, W. M. (2002). Differences in the exploitation of bream in three shallow lake systems and their relation to water quality. Freshwater Biology 47, 2435-2442.

Larkin, P. A. \& Smith, S. B. (1954). Some effects of introduction of redside shiner on the Kamloops trout in Paul Lake, British Columbia. Transactions of the American Fisheries Society 83, 161-175.

Levins, R. (1966). Strategy of model building in population biology. American Scientist 54, 421-431.

Lundwall, D., Svanbäck, R., Persson, L. \& Byström, P. (1999). Size-dependent predation - the interaction between predator foraging and prey avoidance capacities. Canadian Journal of Fisheries and Aquatic Sciences 56, 1-8. 
MacKinnon, J. C. (1973). Analysis of energy flow in an unexploited marine flatfish population. Journal of Fisheries Research Board of Canada 30, 1717-1728.

Metz, J. A. J. \& Diekmann, O. (1986). The Dynamics of Physiologically Structured Populations. Heidelberg: Springer.

Metz, J. A. J., De Roos, A. M. \& Van den Bosch, F. (1988). Population models incorporating physiological structure: a quick survey of the basic concepts and an application to size-structured population dynamics in waterfleas. In Size-structured Populations: Ecology and Evolution (Ebenman, B. \& Persson, L., eds), pp. 106-126. Heidelberg: Springer.

Mittelbach, G. G. (1981). Foraging efficiency and body size: a study of optimal diet and habitat use by bluegills. Ecology 62, 1370-1386.

Mittelbach, G. G. \& Persson, L. (1998). The ontogeny of piscivory and its ecological consequences. Canadian Journal of Fisheries and Aquatic Sciences 55, 1454-1465.

Mylius, S. D., Klumpers, K., De Roos, A. M. \& Persson, L. (2001). Impact of intraguild predation and stage structure on simple communities along a productivity gradient. American Naturalist 158, 259-276.

Noakes, D. L. G. \& Godin, J.-G. J. (1988). Ontogeny of behavior and concurrent developmental changes in sensory systems in teleost fishes. In Fish Physiology, Vol. XIB (Hoar, W. S. \& Randall, D. J., eds), pp. 345-395. New York: Academic Press.

Olson, M. H., Mittelbach, G. G. \& Osenberg, C. W. (1995). Competition between predator and prey: resource-based mechanisms and implications for stage-structured dynamics. Ecology 76, 1758-1771.

Persson, A. \& Brönmark, C. (2002a). Foraging capacities and effects of competitive release on ontogenetic diet shift in bream, Abramis brama. Oikos 97, 271-281.

Persson, A. \& Brönmark, C. (2002b). Foraging capacity and resource synchronization in an ontogenetic diet switcher, pikeperch (Stizostedion lucioperca). Ecology 83, 3014-3022.

Persson, L. (1987). The effects of resource availability and distribution on size class interactions in perch, Perca fluviatilis. Oikos 48, 148-160.

Persson, L. (1988). Asymmetries in competitive and predatory interactions in fish populations. In Size-structured Populations: Ecology and Evolution (Ebenman, B. \& Persson, L., eds), pp. 203-218. Heidelberg: Springer.

Persson, L., Leonardsson, K., De Roos, A. M., Gyllenberg, M. \& Christensen, B. (1998). Ontogenetic scaling of foraging rates and the dynamics of a size-structured consumer-resource model. Theoretical Population Biology 54, 270-293.

Persson, L., Byström, P. \& Wahlström, E. (2000). Cannibalism and competition in Eurasian perch: population dynamics of an ontogenetic omnivore. Ecology 81, 1058-1071.

Persson, L., De Roos, A. M., Claessen, D., Byström, P., Lövgren, J., Sjögren, S., Svanbäck, R., Wahlström, E. \& Westman, E. (2003). Gigantic cannibals driving a whole-lake trophic cascade. Proceedings of the National Academy of Science (USA) 100, 4035-4039.

Persson, L., Claessen, D., De Roos, A. M., Byström, P., Sjögren, S., Svanbäck, R., Wahlström, E. \& Westman, E. (2004a). Cannibalism in a size-structured population: energy extraction and control. Ecological Monographs 74, 135-157.

Persson, L., De Roos, M. \& Bertolo, A. (2004b). Predicting shifts in dynamical regimes in cannibalistic field populations using individual-based models. Proceedings of the Royal Society, London Series B 271, 2489-2493.

Persson, L., Bertolo, B. \& De Roos, A. M. (2006). Temporal stability in size distributions and growth rates of three pike (Esox lucius) populations - a result of cannibalism? Journal of Fish Biology 69, 461-472.

Peters, R. H. (1983). The Ecological Implications of Body Size. Cambridge: Cambridge University Press.

Polis, G. A., Holt, R. D., Menge, B. A. \& Winemiller, K. O. (1996). Time, space and life history: influences on food webs. In Food Webs: Integration of Patterns and Dynamics (Polis, G. A. \& Winemiller, K. O., eds), pp. 435-460. New York: Chapman \& Hall. 
Rice, J. A., Crowder, L. B. \& Marschall, E. A. (1997). Predation on juvenile fishes: dynamic interactions between size-structured predators and prey. In Early Lifehistory and Recruitment in Fish Populations (Chambers, R. C. \& Trippel, E. A., eds), pp. 333-356. London: Chapman \& Hall.

Sanderson, B. L., Hrabik, T. R., Magnuson, J. J. \& Post, D. M. (1999). Cyclic dynamics of a yellow perch (Perca flavescens) population in an oligotrophic lake: evidence for the role of intraspecific interactions. Canadian Journal of Fisheries and Aquatic Sciences 56, 1534-1542.

Schnute, J. T. \& Richards, L. J. (2001). Use and abuse of fishery models. Canadian Journal of Fisheries and Aquatic Sciences 58, 10-17.

Shepherd, J. G. \& Pope, J. G. (2002). Dynamic pools models I: interpreting the past using virtual population analysis. In Handbook of Fish Biology and Fisheries, Vol. 2 (Hart, P. J. B. \& Reynolds, J. D., eds), pp. 127-163. Oxford: Blackwell Publishing.

Sumari, O. (1971). Structure of the perch populations of some ponds in Finland. Annales Zoologica Fennica 8, 406-421.

Townsend, C. R., Sutherland, W. J. \& Perrow, M. R. (1990). A modelling investigation of population cycles in the fish Rutilus rutilus. Journal of Animal Ecology 59, 469-485.

Webb, P. W. (1978). Partitioning of energy into metabolism and growth. In Ecology of Freshwater Production (Gerking, S. D., ed.), pp. 185-214. London: Blackwell Scientific Publication.

Werner, E. E. (1977). Species packing and niche complementarity in three sunfishes. American Naturalist 11, 553-578.

Werner, E. E. (1988). Size, scaling and the evolution of life. In Size-structured Populations: Ecology and Evolution (Ebenman, B. \& Persson, L., eds), pp. 60-81. Heidelberg: Springer.

Wilbur, H. M. (1988). Interactions between growing predators and growing prey. In Size-structured Populations: Ecology and Evolution (Ebenman, B. \& Persson, L., eds), pp. 157-172. Heidelberg: Springer.

van de Wolfshaar, K. E. (2006). Population persistence in the face of size-dependent predation and competition interactions. PhD Thesis, University of Amsterdam, the Netherlands.

van de Wolfshaar, K., De Roos, A. M. \& Persson, L. (2006). Size-dependent interactions inhibit coexistence in intraguild predation systems with life-history omnivory. American Naturalist 168, 62-75.

Yodzis, P. \& Innes, S. (1992). Body size and consumer resource dynamics. American Naturalist 139, 1151-1175. 